\title{
Resíduo de cerâmica vermelha e fíler calcário em compósito de cimento Portland: efeito no ataque por sulfatos e na reação álcali-sílica
}

\author{
Red-clay waste and limestone filler added \\ in Portland cement composite: effects on \\ sulfate attack and alkali-silica reaction
}

\author{
Marcelo Henrique Farias de Medeiros ${ }^{1}$, Diego Jesus Souza ${ }^{2}$, \\ Juarez Hoppe Filho ${ }^{3}$, Cleberson S. Adorno ${ }^{4}$ \\ Valdecir Angelo Quarcioni ${ }^{5}$, Eduardo Pereira ${ }^{6}$
}

\footnotetext{
${ }^{1}$ Universidade Federal do Paraná (UFPR), Centro Politécnico, Programa de Pós-graduação em Eng. de Constr. Civil (PPGECC-UFPR), Av. Cel. Francisco H. dos Santos, s/n., Jardim das Américas, Curitiba, PR. CEP: 81530-900. e-mail: medeiros.ufpr@gmail.com

${ }^{2}$ Universidade Federal do Paraná (UFPR), Bolsista de Mestrado do PPGECC-UFPR.

e-mail: diegojesusdesouza@hotmail.com

${ }^{3}$ Universidade Federal do Oeste da Bahia (UFOB), Centro das Ciências Exatas e das Tecnologias (CCET)

e-mail: juarez.hoppe@gmail.com

${ }^{4}$ Universidade Federal do Paraná (UFPR), Mestrando do PPGECC-UFPR.

e-mail: cleberadorno@yahoo.com.br

${ }^{5}$ Instituto de Pesquisas Tecnológicas do Estado de São Paulo (IPT) - Laboratório de Materiais de Construção Civil. e-mail: quarciva@ipt.br

${ }^{6}$ Universidade Estadual de Ponta Grossa (UEPG), Departamento de Engenharia Civil.

e-mail: engenheiroeduardopereira@gmail.com
}

\section{RESUMO}

O resíduo de cerâmica vermelha (RCV) proveniente de blocos e tijolos é gerado na produção destes artefatos e na indústria da construção civil, quando da execução das vedações verticais. No primeiro caso, o resíduo apresenta menor teor de contaminantes, enquanto no segundo, o resíduo contém maior grau de impurezas devido à estocagem com outros materiais residuais previamente à destinação final. O volume de RCV gerado requer adequada destinação para evitar impactos ambientais, conforme estabelece a Resolução 307 do Conselho Nacional do Meio Ambiente (CONAMA). A potencialidade reativa do RCV com a cal o qualifica para o uso como adição mineral na composição do cimento Portland evitando, assim, a disposição em aterros destinados à resíduos de construção civil. A análise da viabilidade da incorporação do RCV ao cimento Portland requer estudos que envolvam os efeitos sobre a resistência à compressão e, sobretudo, sobre o desempenho da matriz hidratada quando susceptível à ação de interações físico-químicas deletérias. O presente trabalho tem por objetivo avaliar a influência da incorporação do RCV moído na composição do cimento Portland sobre duas propriedades relacionadas à durabilidade do concreto: resistência à ocorrência de reação álcalisílica (RAS) e resistência ao ataque por sulfato de sódio. Para isto, argamassas de cimento CP V - ARI (referência) e composições com a substituição de $10 \%$ do cimento, em massa, por fíler calcário ou RCV, com três diferentes finuras, foram avaliadas quanto à RAS, segundo a NBR 15.577-5/2008, e à expansão decorrente do ataque por sulfato de sódio, conforme a NBR 13.583/2014, com tempos de exposição estendidos para uma avaliação mais criteriosa da degradação. Os resultados evidenciam que o RCV causou aumento na expansão por RAS e, na maior parte dos casos, também aumentou a expansão devido ao ataque por sulfato de sódio. Por outro lado, a maior cominuição do RCV tende a melhorar o desempenho da matriz cimentícia frente às ações deletérias a que foi submetida, ou seja, a maior finura do RCV impacta, positivamente, no comportamento do material frente à degradação. O fíler calcário não influenciou o resultado de expansão por RAS e 
propiciou redução da expansão provocada pelo ataque por sulfato de sódio. A análise em tempos prolongados de exposição (66 dias para o ensaio de RAS e 210 dias para o ensaio de ataque por sulfato) evidenciou que o RCV moído por 1,5 horas possui potencialidade para a sua utilização como adição mineral na composição do material ligante, com tendência a apresentar desempenho similar à matriz de cimento Portland frente ao ataque por sulfato. Com relação à RAS, há que se incrementar a cominuição do RCV moído por 1,5 horas para aproximar, ao máximo, a sua distribuição granulométrica à distribuição do cimento, o que tende a potencializar a capacidade mitigadora desta adição mineral.

Palavras-chave: Ataque por sulfato de sódio, reatividade álcali-sílica, reatividade pozolânica, cimento Portland, resíduo de cerâmica vermelha.

\section{ABSTRACT}

The red-clay waste (RCW) derives from blocks and bricks in their production process and also in the construction industry, when these materials are used in vertical walls. When originated in the production process, the RCW presents a lower degree of impurities, while when originated from construction sites, it contains a greater degree of impurities due to being stored with other residues before its disposal. According to the Brazilian Environmental Council (CONAMA) in its Resolution 307, RCW requires a proper disposal to avoid environmental impacts. The reactive capability of RCW and lime qualifies it to be used as a mineral admixture in Portland cement composition thus avoiding its disposal in landfills for construction waste. The viability of RCW incorporation in Portland cement requires analyses, such as studies of its compressive strength, and moreover of its performance when the hydrated paste is under physical and chemical deleterious interactions. This paper aims to evaluate the influence of milled RCW in Portland cement's composition, emphasizing two properties related to concrete's durability: its resistance to alkali-silica reaction (ASR) and its resistance to sodium sulfate attack. Therefore, CP V - ARI cement mortars (to be used as reference) and compositions of $10 \%$ replacement in cement mass by limestone filler or RCW, in three different fineness, were evaluated for ASR, according to NBR 15.577-5/2008, and for their expansion due to the sodium sulfate attack, according to NBR 13.583/2014. Although, the exposure time was extended aiming a more careful assessment of their degradation. Results showed that RCW increased the expansion caused by ASR, and, in most cases, also increased the expansion due to sodium sulfate attack. On the other hand, a higher comminution of RCW tends to improve the performance of the cementitious matrix when submitted to deleterious action, that is, a greater fineness of RCW has a positive impact on the material behavior under degradation. The limestone filler did not influence the result of expansion by ASR, but caused a reduction of the expansion induced by sodium sulfate attack. The analysis of the extended exposure time (66 days for ASR tests and 210 days for sulfate attack tests) showed that RCW milled for 1.5 hours might potentially be used as a mineral admixture in the binder material's composition, tending to show a similar performance to Portland cement matrix under sodium sulfate attack. Regarding the RAS, and increase in the comminution of RCW milled for 1.5 hours is required to make its particle size distribution similar to the cement's, which tends to enhance the mitigation capacity of this mineral admixture

Keywords: Sulfate attack, alkali-silica reactivity, pozzolanic activity, Portland cement, concrete.

\section{INTRODUÇÃO}

A produção nacional de cimento Portland, em 2013, foi de 70,2 milhões de toneladas, representada em 34\% pelos cimentos do tipo CP II - Z Z $^{1}(20 \%)$ e CP IV (14\%), os quais incorporam adição mineral pozolânica na sua composição (SNIC, 2013). Assumindo que o teor médio de pozolana na composição do cimento do tipo CP II - Z é de $10 \%$ e, no tipo CP IV, de $35 \%$, a demanda aproximada de cinza volante ou argila calcinada para produção destes cimentos foi de 4,8 milhões de toneladas. A estimativa nacional de geração de resíduo de cerâmica vermelha (RCV) na indústria destes artefatos, em 2014, foi de 3,9 a 6,5 milhões de toneladas [1], com base nas informações da Associação Nacional da Indústria Cerâmica (ANICER). A estimativa apresentada pelos autores não considera o montante de resíduo gerado quando da utilização das peças cerâmicas nos

\footnotetext{
${ }^{1}$ A produção de cimento do tipo CP II, em 2013, foi de 41,2 milhões de toneladas. Para fins de estimativa, foi considerado que a terça parte da produção refere-se ao cimento do tipo CP II - Z. O restante da produção, em igual proporção, é atribuída aos tipos CP II - E e CP II - F.
} 
canteiros de obras. Portanto, fica evidente que o passivo ambiental decorrente da cadeia produtiva da cerâmica vermelha é significativo e requer desenvolvimento científico-tecnológico que viabilize meios para a destinação adequada deste resíduo. Atestada a viabilidade da incorporação do RCV na composição do cimento Portland, a sua disponibilidade no mercado permite, no mínimo, duplicar a produção de ligante cimentício pozolânico.

Atualmente, as pesquisas relacionadas ao RCV destinam-se, na maioria, à sua incorporação em argamassa ou concreto não estrutural como agregado miúdo e/ou graúdo. O estudo voltado para a utilização do RCV como adição mineral ativa ainda é incipiente e está baseado na influência decorrente da substituição parcial do cimento Portland pelo resíduo moído sobre a resistência à compressão e tração na flexão. Nota-se que o estudo do RCV a ser utilizado como agregado requer um tratamento mais rústico do material, normalmente realizado em britador de mandíbulas seguido de peneiramento, enquanto que, o uso como adição mineral, além da britagem inicial, necessita de uma cominuição complementar, até a obtenção de um pó cerâmico com distribuição granulométrica compatível com a do cimento Portland.

A cerâmica vermelha é obtida a partir da conformação de uma massa argilosa, submetida a um lento processo de secagem para a retirada de grande parte da água, seguido de calcinação em temperaturas elevadas. Um dos critérios mais tradicionais para classificação das cerâmicas é a cor da massa, que pode ser branca ou vermelha [2]. Atualmente, existem inúmeros tipos de resíduos de cerâmica de argila vermelha que constituem subprodutos da indústria, cada um com diferenças marcadas pela constituição mineralógica, cor e dureza, em grande parte resultante da matéria-prima utilizada, mas também do tratamento térmico a que os produtos foram submetidos.

A dureza desses materiais residuais é um fator importante na seleção do equipamento a ser utilizado na moagem deste tipo de resíduo. Tratando-se de materiais cerâmicos, cuja matéria-prima básica é a argila, o processo de moagem, utilizando moinhos de bolas, é largamente utilizado. O referido processo permite obter uma distribuição granulométrica bastante fina e pode ser realizado a úmido ou a seco. A moagem a úmido é bem menos utilizada por ineficiência do processo. Já a moagem a seco pode ser otimizada com uso de aditivos modificadores de superfície para melhorar o desempenho da cominuição. Cabe destacar que os tempos de moagem excessivamente grandes não correspondem necessariamente a uma maior finura do produto final, pois existe um tempo de moagem adequado para cada material e moinho específico. Ultrapassando-se este tempo não haverá maior rendimento, apenas elevação do custo do processo e desgaste do moinho sem se obter maior finura ou maior reatividade do material, como pode ser observado no trabalho de Vieira [3].

Ao avaliar a reatividade da cerâmica vermelha moída em argamassa de cal aérea, Matias et al. [4] concluíram que este resíduo apresenta alguma atividade pozolânica com base nos incrementos de resistência à compressão que chegaram a 500\% entre 60 e 120 dias de idades, quando o agregado miúdo (areia de rio) foi substituído parcialmente por teores, em volume, de $20 \%$ e $40 \%$ por material cerâmico cominuído. Em pastas com cimento Portland, Farias Filho et al. [5], ao avaliar a substituição parcial do cimento por tijolo queimado moído, em teores entre 20 e 40\%, em massa, obtiveram aumento da resistência à compressão comparado com a mistura de referência, porém para teores de substituição acima de $20 \%$, houve decréscimo na resistência à flexão. Os autores também constataram que o resíduo estudado apresenta considerável interação química com a cal formada pela hidratação do cimento. Estes dados indicam que esta questão precisa ser melhor investigada para se emitirem constatações mais objetivas e enfáticas sobre o efeito pozolânico da cerâmica moída.

O trabalho de Garcia et al. [1], voltado para a reatividade do RCV, constatou que a capacidade de fixar deste resíduo, quando as partículas são inferiores à $75 \mu \mathrm{m}$, classifica o material como pozolânico, com consumo de cal similar ao observado para a cinza volante [6], amplamente utilizada na composição do cimento Portland pozolânico.

Neste contexto, o presente trabalho visa ampliar o conhecimento sobre a utilização do RCV como adição mineral pozolânica ao cimento Portland e a sua influência em algumas propriedades relacionadas à durabilidade da matriz cimentícia quando exposta à ações deletérias. Por outro lado, a viabilização da utilização do RCV como constituinte do cimento Portland insere este material nos preceitos da sustentabilidade, haja vista a redução da emissão de dióxido de carbono para atmosfera quando da produção de uma determinada quantidade de material ligante, além da adequada destinação do resíduo da indústria cerâmica. Portanto, estudos voltados ao tema são imprescindíveis para aprimorar o uso do RCV na composição do cimento Portland, buscando garantir o adequado desempenho dos componentes estruturais executados com este material 
ligante e, consequentemente, mitigando o impacto ambiental da indústria cimenteira e cerâmica.

\section{JUSTIFICATIVA DO ESTUDO DA INCORPORAÇÃO DE RESÍDUO DE CERÂMICA VERMELHA EM COMPÓSITO DE CIMENTO PORTLAND}

A indústria da construção civil é reconhecidamente de elevado impacto ambiental e qualquer estudo que foque a possibilidade de aproveitamento de resíduos gerados em seu próprio processo de produção é relevante, pois caso haja viabilidade, pode se transformar em uma ferramenta importante para preservar recursos naturais, reduzir custos de produção das edificações e ainda melhorar alguma característica dos materiais comumente utilizados.

Neste contexto, este trabalho visa divulgar informações sobre uma alternativa de aproveitamento de resíduo de cerâmica vermelha, proveniente de tijolos e blocos cerâmicos, em compósito de cimento Portland. Este tema tem sido estudado em outros trabalhos [7-11], onde foram comparadas propriedades como: resistência à compressão, tração por compressão diametral, resistência à flexão, módulo de elasticidade, absorção de água, retração, porosidade aparente e variações dimensionais por oscilação de umidade. As comparações sempre são feitas entre concretos com agregados oriundos de resíduos de cerâmica e concretos moldados com agregados comumente utilizados, provenientes da britagem de rocha.

Os trabalhos de Senthamarai et al. de 2005 [7], de Senthamarai et al. de 2011 [8] e Cabral et al. de 2009 [9] seguem a proposta de incorporação do resíduo de cerâmica como agregados e os resultados obtidos indicam que as características dos concretos compostos por estes materiais, como a trabalhabilidade e a resistência mecânica, podem ser equivalentes aos concretos convencionais. Os trabalhos de Senthamarai e Manoharan [7-8] são relacionados ao uso do resíduo como agregado graúdo e cerâmica branca, enquanto o trabalho de Cabral [9] trata de emprego de cerâmica vermelha como agregado miúdo e como agregado graúdo. Por outro lado, Brito et al. [10] mostraram que o emprego de cerâmica vermelha como agregado graúdo resultou em uma queda na resistência à compressão e à flexão, porém resultou na elevação da resistência à abrasão.

Com um foco diferente, Oliveira et al. [11] desenvolveram um estudo em que determinaram a atividade pozolânica, assim como, a resistência à compressão aos 7, 28 e 90 dias de argamassas compostas com adições de cerâmica vermelha de finura entre 75 - $150 \mu \mathrm{m}$ em substituição parcial ao cimento, em teores entre 10 e $40 \%$. Segundos os autores, o pó cerâmico oriundo da telha vermelha apresentou grande potencial pozolânico, todavia, tanto a argamassa produzida com pó cerâmico de telhas vermelhas, como a produzida com pó de tijolos vermelhos apresentaram redução de resistência à compressão quando comparadas à argamassa de referência. É possível que esta tendência de comportamento esteja relacionada à reatividade pozolânica do resíduo, incapaz de suprir o decréscimo de resistência oriundo da substituição parcial do cimento. Este comportamento também é observado quando se utiliza a cinza volante na composição do cimento, a qual apresente nível de reatividade similar ao resíduo cerâmico.

Verificou-se que nenhum dos trabalhos citados objetivou entender o efeito que a incorporação destes produtos pode ter na capacidade do compósito em desenvolver reação álcali-sílica, assim como resistir ao ataque de sulfato de sódio, ambos os fenômenos de suma importância em muitas aplicações do concreto e essenciais no estudo da durabilidade de concreto. Este é o argumento utilizado para evidenciar a relevância deste trabalho, pois a durabilidade do concreto deve ser sempre avaliada da forma mais ampla possível antes de atestar a real viabilidade de implementação de um processo ou procedimento no mercado da construção civil.

\section{PROCEDIMENTO EXPERIMENTAL}

Para avaliar o efeito da incorporação de resíduo de cerâmica vermelha em compósito de cimento Portland utilizou-se um material cerâmico oriundo de rejeitos de blocos cerâmicos (tijolos de cerâmica vermelha). Os blocos passaram por um pré-beneficiamento em britador de mandíbula e, posteriormente, foram moídos em moinhos de bola por períodos de 0,5; 1,0 e 1,5 horas.

Para os ensaios de avaliação da mitigação da reação álcali-sílica utilizaram-se os procedimentos sugeridos pela NBR 15.577-5/2008 [12] e, para o ensaio com sulfato de sódio, foi empregado o procedimento da NBR 13.583/2014 [13]. 
Para se estabelecerem as comparações, foram empregadas duas argamassas de referência, uma sem qualquer adição e outra com adição de fíler calcário. Para todos os casos, o percentual de substituição parcial do cimento foi fixado em $10 \%$ em massa. O teor de $10 \%$ foi utilizado por representar a média da faixa de teores permissíveis (6 14\%) para material pozolânico a ser incorporado na composição do cimento Portland do tipo CP II - Z, conforme a norma NBR 11.578/1991 [14].

\subsection{Materiais}

\subsubsection{Cimento}

O cimento Portland utilizado foi do tipo CP V - ARI (similar ao cimento tipo III - High Early Strength, conforme a ASTM C150), pois este é o mais utilizado em ensaios que visam medir a reatividade dos agregados quanto à reação álcali-sílica, além de ser o cimento com o menor teor de adições em fábrica, com o maior teor de $\mathrm{C}_{3} \mathrm{~A}$ e, consequentemente, o mais crítico com relação ao ataque por sulfatos.

As características químicas e físicas do cimento utilizado estão apresentadas na Tabela 1, obtidas empregando-se métodos de ensaio normalizados no país. Os dados de $\mathrm{SiO}_{2}, \mathrm{CaO}, \mathrm{MgO}, \mathrm{Fe}_{2} \mathrm{O}_{3}, \mathrm{Al}_{2} \mathrm{O}_{3}$ e $\mathrm{SO}_{3}$ foram obtidos por fluorescência de Raios-X. A massa específica do cimento é de $3,12 \mathrm{~g} / \mathrm{cm}^{3}$, determinada de acordo com a NBR NM 23/2001 [15].

Tabela 1: Resultados de caracterização do cimento CP V - ARI.

\begin{tabular}{|c|c|c|c|c|c|c|c|c|c|c|c|c|}
\hline \multicolumn{13}{|c|}{ Análise Química, em \% } \\
\hline Parâmetros & $\mathrm{SiO}_{2}$ & $\mathrm{CaO}$ & $\mathrm{MgO}$ & $\mathrm{Fe}_{2} \mathrm{O}_{3}$ & $\mathrm{Al}_{2} \mathrm{O}_{3}$ & $\mathrm{SO}_{3}$ & $\begin{array}{c}\text { Perda ao } \\
\text { Fogo }\end{array}$ & $\mathrm{CaO} \mathrm{L}$ & & & $\begin{array}{l}\text { íduo } \\
\text { lúvel }\end{array}$ & $\begin{array}{l}\text { Álcalis totais } \\
\text { como } \mathrm{Na}_{2} \mathrm{Oe}^{*}\end{array}$ \\
\hline Resultados & 18,34 & 59,72 & 5,35 & 2,52 & 4,12 & 3,05 & 3,2 & 1,4 & & & 63 & 0,62 \\
\hline \multicolumn{13}{|c|}{ Ensaios Físicos } \\
\hline \multirow{3}{*}{ Parâmetros } & \multirow{2}{*}{$\begin{array}{c}\text { Exp. } \\
\text { Quente }\end{array}$} & \multirow{2}{*}{$\begin{array}{c}\text { Início de } \\
\text { pega }\end{array}$} & \multirow{2}{*}{$\begin{array}{c}\text { Fim de } \\
\text { pega }\end{array}$} & \multirow{2}{*}{$\begin{array}{l}\text { Cons. } \\
\text { Normal }\end{array}$} & \multirow{2}{*}{$\begin{array}{l}\text { Finura } \\
\text { Blaine }\end{array}$} & \multicolumn{2}{|c|}{ Retido em } & \multicolumn{5}{|c|}{ Resistência à compressão } \\
\hline & & & & & & \# 200 & \# 325 & 1 dia & $3 d$ & & $7 \mathrm{dia}$ & 28 dias \\
\hline & $\mathrm{mm}$ & h:min & h:min & $\%$ & $\mathrm{~m}^{2} / \mathrm{kq}$ & $\%$ & $\%$ & MPa & M & & $\mathrm{MPa}$ & $\mathrm{MPa}$ \\
\hline Resultados & 0,5 & 02:15 & 03:00 & 27,6 & 437 & 0,10 & 2,80 & 23,40 & 37 & & 42,7 & 51,10 \\
\hline
\end{tabular}

*Óxido de sódio equivalente $\left(\mathrm{Na}_{2} \mathrm{O}_{\mathrm{e}}\right)=\mathrm{Na}_{2} \mathrm{O}+0,658 \mathrm{~K}_{2} \mathrm{O}$

\subsubsection{Agregados}

Reação álcali-sílica:

O agregado miúdo selecionado para o experimento, procedente da região metropolitana de Curitiba, foi caracterizado por Tiecher [16] e utilizado por Valduga [17], sendo classificado como granito proveniente de rocha potencialmente reativa, com expansão entre $0,1 \%$ e $0,2 \%$ aos 16 dias, de acordo com especificações da ASTM C 1260/2007 [18]. Este mesmo agregado apresenta histórico de manifestações patológicas diagnosticadas como reação álcali-agregado em obras hidráulicas nacionais.

O agregado utilizado foi processado com o mínimo necessário de britagem, utilizando-se um aparelho de Abrasão Los Angeles. Com o peneiramento do material britado, obtiveram-se as faixas granulométricas requeridas na NBR 15.577-4/2008 [19], que são as retidas nas peneiras: 2,36 mm, 1,18 mm, 0,60 mm, 0,30 $\mathrm{mm}$ e $0,15 \mathrm{~mm}$.

Ataque por sulfato de sódio:

Neste caso, por exigência da norma NBR 13.583/2014 [13], foi empregada areia normal, cujas frações são: \# 0,15 mm; \# 0,30 mm; \# 0,60 mm; e \# 1,18 mm. 
3.1.3 Resíduo de cerâmica e fíler calcário

O material cerâmico utilizado é oriundo de blocos de 6 e 8 furos de cerâmica vermelha provenientes de olarias da região de Prudentópolis, PR. Os blocos foram triturados em britador de mandíbula da marca Furlan para obtenção de $100 \%$ de material passante pela peneira de abertura 4,8 mm. Após a britagem, o material passante na peneira 4,8 mm foi moído em moinho de bolas da marca Gardelini, durante os tempos determinados: 0,5; 1,0 e 1,5 horas. A massa específica média da cerâmica moída empregada neste estudo é 2,60 $\mathrm{g} / \mathrm{cm}^{3}$.

O fíler calcário utilizado é proveniente da fábrica Itaú de Minas da Votorantim Cimentos, sendo normalmente utilizado na produção de cimentos e argamassas. A massa específica deste material é 2,70 g/ $\mathrm{cm}^{3}$.

A composição química do material cerâmico e do fíler calcário são apresentadas na Tabela 2.

Tabela 2: Resultados da composição química do material cerâmico e do fíler calcário.

\begin{tabular}{c|c|c|c|c|c|c|c|c|c|c|c}
\hline \multirow{2}{*}{ Material } & \multicolumn{10}{c}{ Composição química, em \% } \\
\cline { 2 - 11 } & $\mathrm{SiO}_{2}$ & $\mathrm{CaO}$ & $\mathrm{MgO}^{*}$ & $\mathrm{Fe}_{2} \mathrm{O}_{3}$ & $\mathrm{Al}_{2} \mathrm{O}_{3}$ & $\mathrm{~K}_{2} \mathrm{O}$ & $\mathrm{SO}_{3}$ & $\mathrm{TiO}_{2}$ & $\mathrm{ZnO}$ & $\mathrm{MnO}$ & $\begin{array}{c}\text { Álcalis totais } \\
\text { como } \mathrm{Na}_{2} \mathrm{Oe}^{*}\end{array}$ \\
\hline Fíler calcário & 2,97 & 78,03 & 15,06 & 0,44 & 1,73 & 0,31 & 1,21 & - & - & 0,11 & 0,20 \\
\hline Material cerâmico & 55,32 & 0,19 & - & 5,27 & 35,50 & 1,28 & 1,23 & 1,09 & 0,01 & 0,04 & 0,84 \\
\hline
\end{tabular}

\subsection{Detalhamento dos ensaios}

Os materiais investigados como adições minerais para compósitos de cimento Portland foram submetidos à determinação do índice de atividade pozolânica (IAP) com cal [20] e índice de atividade pozolânica (IAP) com cimento [21], para quantificar o potencial reativo, e caracterizados por difratometria de raios-X (DRX) para identificação das fases cristalinas e, também, do halo amorfo que sinaliza a potencialidade reativa das adições. Além disso, foram determinadas as curvas granulométricas por difração a laser e a área superficial específica pela técnica de BET.

O método de IAP com cal prescreve a moldagem de três corpos de prova cilíndricos de $\phi 50$ x $100 \mathrm{~mm}$ e posterior ruptura à compressão, aos 7 dias. O ensaio foi realizado em argamassa moldada com a adição mineral em teste, areia normal da ABNT (234 g de cada fração 1,2; 0,6; 0,3 e 0,15 mm), 104 g de hidróxido de cálcio p.a. e a água necessária para se obter a consistência da argamassa em $225 \pm 5 \mathrm{~mm}$. A quantidade de adição é calculada de acordo com a Eq. 1.

$m_{a d}=2 \cdot \frac{M E_{a d}}{M E_{c a l}} \cdot 104$ (em gramas)

Eq. 1

Onde: $m_{a d}$ é a massa da adição mineral em teste, $M E_{a d}$ é a massa específica da adição, $\mathrm{ME}_{\mathrm{cal}}$ é a massa específica da cal.

O IAP com cal indica que a adição é pozolânica quando o resultado atingir, no mínimo, 6,0 MPa.

No caso do IAP com cimento Portland são preparadas uma argamassa de referência, que contém apenas cimento Portland, e mais uma para cada adição mineral em teste, de modo a se ter 35\% do volume absoluto de cimento substituído pelo material pozolânico. É realizada a moldagem de três corpos de prova cilíndricos de $\phi 50$ x 100 mm para cada argamassa. A argamassa de referência é composta por 312 g de cimento Portland e 936 g de areia normal, dividida em iguais porções das quatro frações que a constitui, e a argamassa com o material possivelmente pozolânico é composta por 202,8 g de cimento, a massa da adição em teste, determinada por meio da Eq. 2, e 936 g de areia normal. A água utilizada em cada caso é a necessária para se obter a consistência da argamassa de $225 \pm 5 \mathrm{~mm}$. O cálculo da quantidade de adição mineral a ser utilizada na composição da argamassa para o IAP com cimento segue a Eq. 2.

$m_{a d}=109,2 \cdot \frac{M E_{a d}}{M E_{c}}$

Eq. 2

Onde: $\mathrm{m}_{\mathrm{ad}}$ é a massa da adição mineral em teste, $\mathrm{ME}_{\mathrm{ad}}$ é a massa específica da adição, $\mathrm{ME}_{\mathrm{c}}$ é a massa específica do cimento.

O preparo da amostra para a coleta do difratograma foi realizado por prensagem manual do pó no porta-amostra, seguido de exposição aos raios-X no difratômetro RIGAKU modelo Ultima IV. A mensuração 
foi realizada entre $5^{\circ}$ e $75^{\circ} 2 \theta$, com passo angular de $0,02^{\circ} 2 \theta$ e tempo por passo de 1 segundo. Na coleta se utilizou tubo com ânodo de cobre, $40 \mathrm{kV} / 30 \mathrm{~mA}$, e fenda divergente de $1^{\circ}$.

\subsubsection{Reação Álcali-sílica (NBR 15.577-5/2008)}

O experimento foi realizado de acordo com a NBR 15.577-5/2008 - Determinação da mitigação da expansão em barras de argamassa pelo método acelerado [12].

O procedimento de mistura das argamassas seguiu as recomendações da referida norma técnica no que diz respeito à ordem de mistura dos materiais, ao tempo de mistura, à moldagem das barras, aos procedimentos de cura inicial e desfôrma das barras de argamassa.

Segundo a NBR 15.577-4/2008 [19], a quantidade de cimento para o ensaio deve ser de $440 \mathrm{~g}$ e a de agregado de $990 \mathrm{~g}$, representada pela soma das várias faixas granulométricas, para relação a/c $=0,47$. Para este estudo foram mantidas as proporções de materiais recomendadas na norma, porém em quantidade total superior para viabilizar a moldagem de 6 barras de argamassa para cada série de ensaio de modo a proporcionar maior representação estatística dos resultados, pois a NBR 15.577-5/2008 [12] prescreve o uso de apenas 3 barras. Adotou-se o teor de substituição de $10 \%$ em relação à massa de cimento Portland, tanto para o fíler calcário como para a cerâmica vermelha, com os diferentes tempos de moagem. As quantidades de frações de agregados, cimento e adições encontram-se na Tabela 3.

As barras ficaram imersas todo período de ensaio em solução de $\mathrm{NaOH}$ p.a., na concentração de $40 \mathrm{~g}$ para cada litro de água destilada empregando-se um banho termorregulador com temperatura controlada e mantida em $(80 \pm 2)^{\circ} \mathrm{C}$. Para cada idade de leitura, as barras foram retiradas das soluções e colocadas novamente dentro do banho termorregulador em um período máximo de 10 minutos.

A NBR 15.577-5/2008 [12] recomenda leituras iniciais, incluindo as idades de 16 e 30 dias. Visando uma avaliação mais completa da expansão das barras, foram realizadas leituras nos primeiros 66 dias, duas vezes por semana, incluindo o $16^{\circ}$ e o $30^{\circ}$ dias de ensaio. $\mathrm{O}$ aparato utilizado para as medições foi um pórtico metálico com um relógio comparador de comprimento, com precisão de 0,001 mm.

Tabela 3: Dosagem dos materiais utilizados no ensaio de reação álcali-sílica.

\begin{tabular}{c|c|c}
\hline Material & Quantidade & Porcentagem \\
\hline Cimento CP V ARI & $792,0 \mathrm{~g}$ & $90 \%$ \\
\hline Adição mineral (fíler calcário ou cerâmica moída) & $88,0 \mathrm{~g}$ & $10 \%$ \\
\hline Material ligante (cimento + adição mineral) & $880,0 \mathrm{~g}$ & $100 \%$ \\
\hline \hline Água (a/c = 0,47) & $413,6 \mathrm{~g}$ & --- \\
\hline Agregado miúdo & $1.980,0 \mathrm{~g}$ & $100 \%$ \\
\hline Agregado retido \# 2,36 mm & $198,0 \mathrm{~g}$ & $10 \%$ \\
\hline Agregado retido \# 1,18 mm & $495,0 \mathrm{~g}$ & $25 \%$ \\
\hline Agregado retido \# 0,60 mm & $495,0 \mathrm{~g}$ & $25 \%$ \\
\hline Agregado retido \# 0,30 mm & $495,0 \mathrm{~g}$ & $25 \%$ \\
\hline Agregado retido \# 0,15 mm & $297,0 \mathrm{~g}$ & $15 \%$ \\
\hline * A argana
\end{tabular}

3.2.2 Ataque por sulfato de sódio (NBR 13.583/2014)

A eficiência em mitigar o ataque por sulfatos das adições estudadas foi avaliada através da determinação da variação dimensional de barras de argamassa de cimento Portland expostas à solução de sulfato de sódio, conforme preconiza a NBR 13.583/2014 [13]. As argamassas, na proporção de 1:3,2 (cimento:agregado miúdo - areia normal brasileira), em massa, foram moldadas com a relação água/material ligante igual a 0,60, onde o volume de água foi estabelecido em relação à soma das massas de cimento e adição mineral. A referida norma estabelece, para cada série de 4 corpos de prova, uma massa de 500 gramas de cimento. A composição do material ligante, para todas as séries, resulta no consumo de 450 gramas de cimento CP V - ARI e 50 gramas de adição mineral, o que mantém o volume de água de amassamento constante, ou seja, $300 \mathrm{ml}$. A 
massa de areia normal brasileira [22] para a mistura é de 1.600 gramas, composta por 400 gramas de cada fração granulométrica. O aumento ou a diminuição da expansão linear da barra de argamassa, devido ao ataque da solução de sulfato de sódio em relação à expansão de barras da mesma argamassa curada em água saturada de cal, indica o potencial das adições minerais em mitigar a degradação da matriz hidratada pela ação dos íons sulfato.

\section{RESULTADOS E DISCUSSÃO}

Os resultados estão divididos em: caracterização dos materiais, resultados de reação álcali-sílica e de resistência aos sulfatos, como apresentados a seguir.

\subsection{Finura dos materiais empregados}

A finura das adições minerais apresenta papel relevante no comportamento e reatividade do compósito de cimento Portland. O cimento, fíler calcário e cerâmica moída, para os três tempos de moagem (0,5; 1,0 e 1,5 horas) foram caracterizados quanto à distribuição granulométrica e área superficial específica BET. A Figura 1 apresenta a distribuição granulométrica dos materiais e na Tabela 4 constam os resultados de determinação da área superficial específica pelo método BET e o diâmetro médio das partículas.

A área superficial específica BET da cerâmica moída é cerca de 12 vezes maior que a área do cimento, independente do tempo de moagem. A área superficial específica BET do fíler calcário é 9 vezes menor que a cerâmica vermelha. Cabe destacar que o maior tempo de moagem e, consequentemente, a maior finura, não alterou significativamente a área superficial específica BET do RCV. Por outro lado, a técnica de granulometria a laser indicou que o tempo de moagem influencia a distribuição granulométrica dos grãos, com aumento da finura do material à medida que se elevou o tempo de moagem.

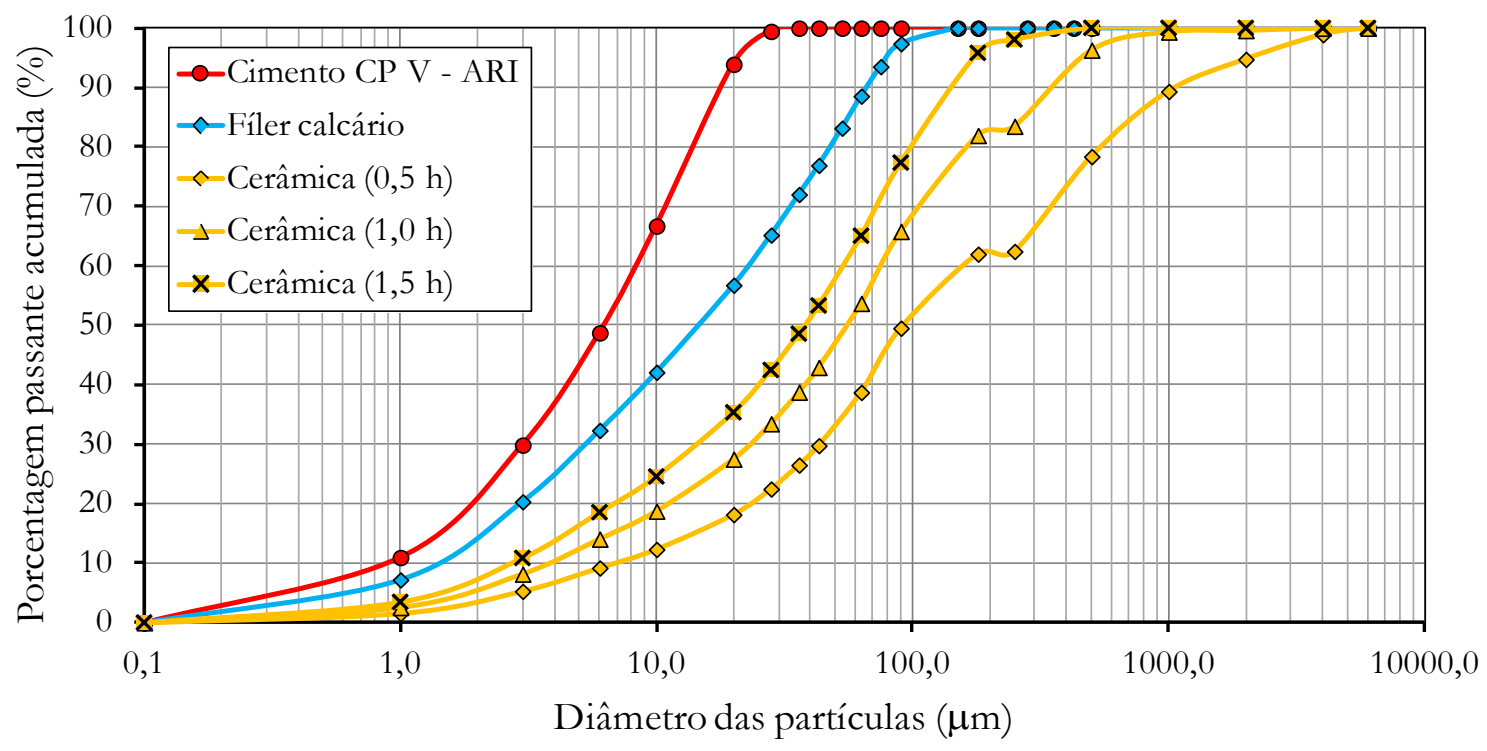

Figura 1: Distribuição granulométrica das adições em comparação com o cimento empregado.

Tabela 4: Área superficial específica BET dos materiais em estudo.

\begin{tabular}{c|c|c}
\hline Material & $\begin{array}{c}\text { Área superficial específica BET } \\
\left(\mathbf{m}^{2} \mathbf{l g}\right)\end{array}$ & $\begin{array}{c}\text { Diâmetro médio das partículas } \\
(\boldsymbol{\mu} \mathbf{m})\end{array}$ \\
\hline Cimento CPV-ARI & 1,1 & 6,3 \\
\hline Fíler calcário & 1,4 & 15,4 \\
\hline Material cerâmico 0,5h & 12,9 & 93,3 \\
\hline Material cerâmico 1,0h & 13,0 & 56,1 \\
\hline Material cerâmico 1,5h & 13,0 & 38,1 \\
\hline
\end{tabular}




\subsection{Atividade pozolânica das adições minerais}

Para verificação do potencial pozolânico dos resíduos provenientes de cerâmica vermelha foram realizados o ensaio Chapelle modificado [23], o IAP com cal [20] e o IAP com cimento [21].

\subsubsection{Ensaio Chapelle modificado}

A Tabela 5 apresenta os valores do ensaio Chapelle modificado para as amostras de cerâmica com diferentes finuras. No caso do fíler calcário, o método não é aplicável por não se tratar de um material silicoso, aluminoso ou sílico-aluminoso. O fíler calcário não tem a ação típica das pozolanas, pois não ocorre a fixação de cal por meio de reação química originando silicato de cálcio hidratado.

Raverdy et al. [24] estudaram a absorção de cálcio por amostras de pozolanas obtendo o valor mínimo indicativo de $330 \mathrm{mg} \mathrm{CaO} / \mathrm{g}$ amostra [ou $436 \mathrm{mg} \mathrm{Ca}(\mathrm{OH})_{2} / \mathrm{g}$ amostra] para um material ser considerado potencialmente pozolânico. Neste estudo, os ensaios eram realizados empregando-se a proporção 1:1 (CaO:pozolana).

Recentemente, as normas brasileira e francesa, respectivamente, NBR 15.895/2010 [23] e NF P18.513/2012 [25] foram revisadas e incorporaram uma modificação significativa ao adotar a proporção de 2:1 (CaO:pozolana), com ganho na eficiência do ensaio e o resultado passou a ser expresso em mg $\mathrm{Ca}(\mathrm{OH})_{2} / \mathrm{g}$ pozolana.

A reatividade do RCV nas diferentes finuras, determinada pela NBR 15.895/2010 [23], indicou, com base no limite mínimo proposto por Raverdy et al. [24] (436 $\mathrm{mg} \mathrm{Ca}(\mathrm{OH})_{2} / \mathrm{g}$ pozolana), que as amostras analisadas possuem alguma reatividade, com valores próximos ao limite mínimo. Cabe destacar que a moagem incrementou o consumo de cal do RCV, apesar da área superficial específica BET não ter variado consideravelmente com a cominuição.

Tabela 5: Ensaio Chapelle, conforme a norma NBR 15.895/2010, dos materiais em estudo.

\begin{tabular}{c|c|c}
\hline Material & $\begin{array}{c}\text { Teor de } \mathbf{C a}(\mathrm{OH})_{2} \text { fixado } \\
\left(\mathbf{m g ~ C a}(\mathbf{O H})_{2} / \mathbf{g} \text { amostra) }\right.\end{array}$ & $\begin{array}{c}\text { Incremento na reatividade com a finura } \\
\text { (\%) }\end{array}$ \\
\hline Material cerâmico 0,5h & 454 & -- \\
\hline Material cerâmico 1,0h & 516 & 14,0 \\
\hline Material cerâmico 1,5h & 537 & 18,0 \\
\hline
\end{tabular}

\subsection{2 Índice de Atividade Pozolânica (IAP) com cal}

A Figura 2 apresenta os resultados de resistência à compressão das argamassas de cal contendo fíler calcário ou o material cerâmico em prol da determinação do índice de atividade pozolânica com cal [20]. A relação água/materiais ligantes (hidróxido de cálcio + adição mineral) da argamassa com fíler calcário foi de 0,51, enquanto para o RCV, independentemente da finura, a relação foi de 0,43. A argamassa com adição mineral inerte, apresentou resistência à compressão abaixo do mínimo de 6,0 MPa preconizado pela NBR 12.653/2012 [26]. De fato, este comportamento previsível evidencia não haver atividade química significativa entre o hidróxido de cálcio e o fíler calcário e, desta forma, esta adição não é classificada como pozolana.

As argamassas com adição de material cerâmico, independente do tempo de moagem, também apresentaram resistências à compressão inferiores ao mínimo preconizado pela norma, indicando, por esta metodologia, que tal adição, independente dos níveis de finura usados neste trabalho, não pode ser classificada como pozolana. Estes resultados estão compatíveis com os obtidos por Oliveira et al. [11] quanto à classificação de atividade pozolânica. 


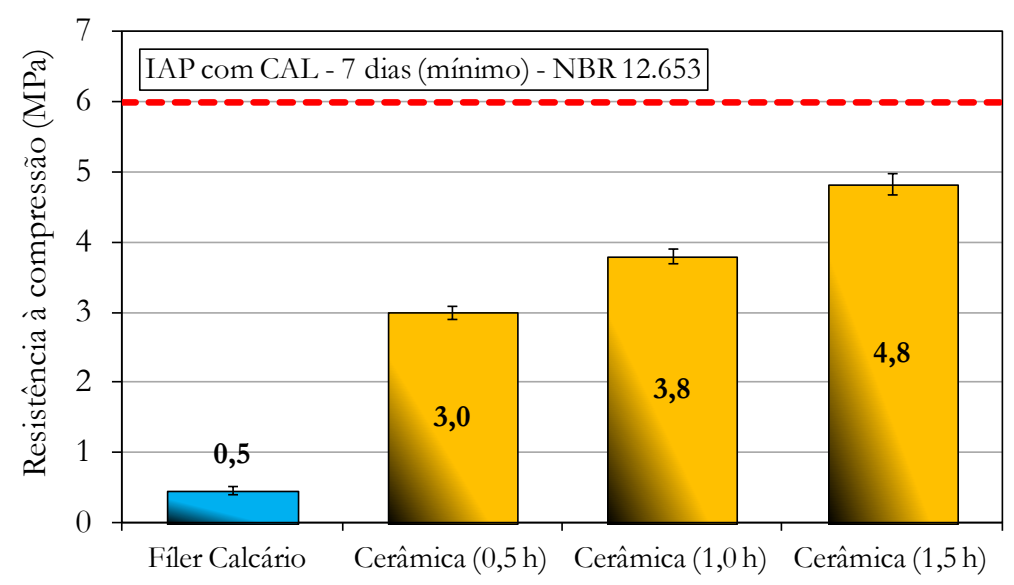

Figura 2: Resultado do índice de atividade pozolânica (IAP) com cal.

\subsection{3 Índice de Atividade Pozolânica (IAP) com cimento Portland}

O IAP com cimento Portland, conforme a NBR 5.752/2012 [21], requer que as argamassas disponham, no estado fresco, de consistência pré-estabelecida (225 $\pm 5 \mathrm{~mm}$ ), o que resulta em variados volumes de água de amassamento em função das características físico-químicas das adições minerais. A norma NBR 12.653/2012 [26] estabelece como limite um adicional de 10 a $15 \%$ sobre o volume de água de mistura da argamassa de referência, o que impacta na resistência à compressão da argamassa. A Figura 3 apresenta a demanda de água das argamassas quando da substituição parcial do cimento por fíler calcário ou RCV, com as diferentes finuras. A argamassa de referência, somente com cimento, foi moldada na relação água/cimento igual a 0,48 (150 gramas de água). O fíler calcário aumentou em $6 \%$ a demanda de água em comparação à argamassa de referência, enquanto a cerâmica vermelha, com as diferentes finuras, reduziu a demanda, em média, para um proporcional de $75 \%$. De fato, a redução na demanda de água por parte da cerâmica vermelha potencializa a resistência à compressão da argamassa, a ser avaliada a seguir.

As resistências à compressão das argamassas de cimento Portland [21], com e sem o fíler calcário e os materiais cerâmicos, são apresentadas na Figura 4. A argamassa de referência atingiu, em média, a resistência à compressão de $41,1 \mathrm{MPa}$, enquanto a substituição de $35 \%$ do volume de cimento por fíler calcário reduziu a resistência para aproximadamente 23,2 MPa. A norma NBR 12.653/2012 [26] estabelece um percentual mínimo de $75 \%$ da resistência à compressão da argamassa de referência para atribuir potencial pozolânico à adição mineral ensaiada. Assim sendo, para o cimento estudado, as argamassas com adições minerais devem atingir uma resistência mínima de 30,8 MPa, o que não ocorreu com a argamassa contendo filer calcário, nem tampouco, com as amostras contendo material cerâmico. Portanto, não são consideradas pozolanas, estando de acordo com o ensaio de IAP com cal [20].

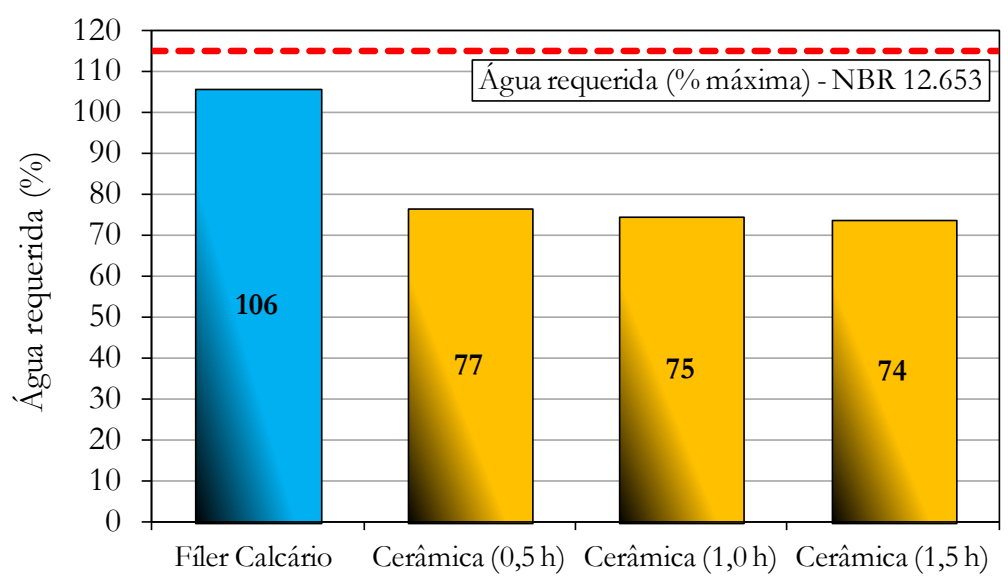

Figura 3: Demanda percentual de água de amassamento das argamassas de cimento Portland contendo adições minerais em relação à argamassa de referência. 
Cabe destacar que a cerâmica moída por 1,5 horas atingiu resistência à compressão próxima ao valor limite para a classificação como pozolana. Este comportamento está relacionado, principalmente, à menor demanda de água de mistura para atingir a consistência pré-estabelecida na metodologia normativa, embora de acordo com os resultados do ensaio Chapelle modificado seja evidente que há influência da interação química da cerâmica vermelha com a portlandita. Como a variação na demanda de água de mistura nas três argamassas com cerâmica vermelha é muito pequena, o que está condizente com os resultados da área superficial específica BET, o incremento na resistência à compressão deve estar associado à maior interação das partículas da adição com o hidróxido de cálcio, com decorrente formação de um teor maior de silicato de cálcio hidratado, responsável, diretamente, pela capacidade portante do material.

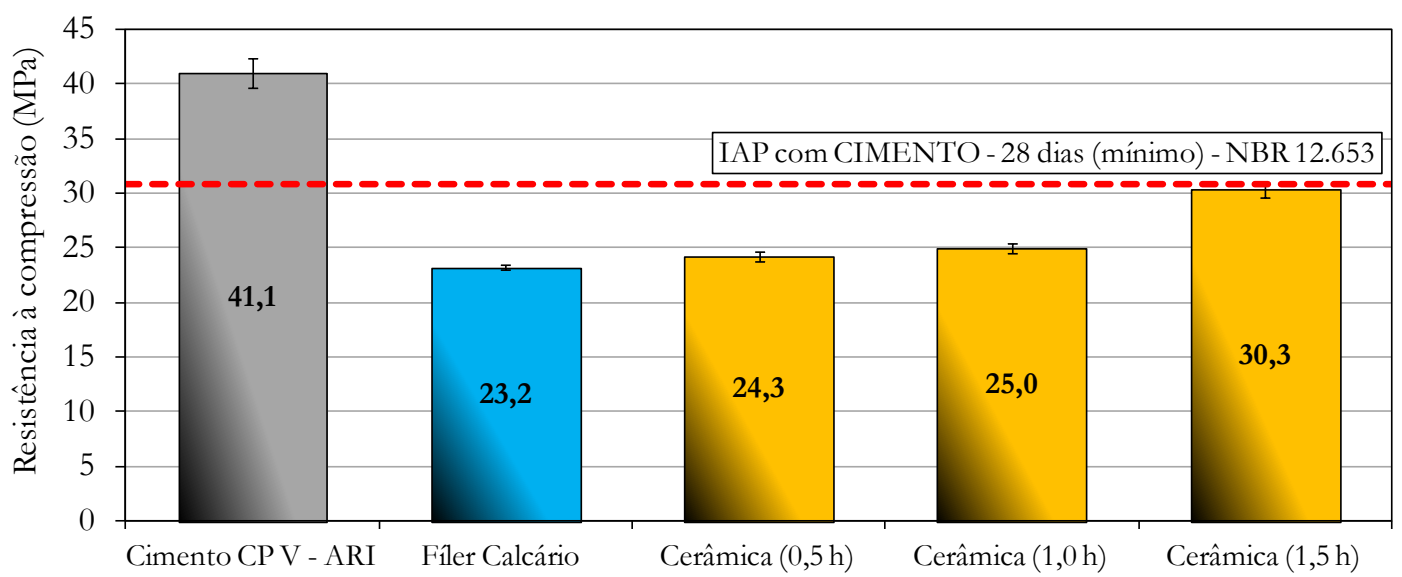

Figura 4: Resultado do índice de atividade pozolânica (IAP) com cimento.

A Figura 5 apresenta o difratograma de raios-X do fíler calcário. Usando os dados do International Centre for Diffraction Data (ICDD) para identificação dos constituintes desta adição, foram encontrados picos característicos que indicam a presença de calcita $\left(\mathrm{CaCO}_{3}\right)$, dolomita $\left(\mathrm{CaCO}_{3} \cdot \mathrm{MgCO}_{3}\right)$ e quartzo $\left(\mathrm{SiO}_{2}\right)$. $\mathrm{Na}$ amostra de material cerâmico (difratograma da Figura 6) foram encontrados picos típicos que revelam a existência de quartzo $\left(\mathrm{SiO}_{2}\right)$, ilita $\left(\mathrm{K} \cdot \mathrm{Al}_{2} \cdot\left(\mathrm{Si}_{3} \cdot \mathrm{Al}\right) \cdot \mathrm{O}_{10} \cdot(\mathrm{OH})_{2}\right)$ e hematita $\left(\mathrm{Fe}_{2} \mathrm{O}_{3}\right)$.

No fíler calcário não há evidência da presença de halo amorfo no difratograma, evidenciando que tal adição apresenta um elevado grau de cristalinidade. Apesar disto, devido à finura do material, este pode ser utilizado como material de enchimento, melhorando o empacotamento das partículas nas misturas e contribuindo para melhor densificação dos compósitos cimentícios. A cerâmica vermelha apresenta um tênue halo amorfo, coerente com a sua restrita capacidade de reação com a cal, formando compostos hidratados, como verificado pelo ensaio Chapelle e também no IAP com cal e no IAP com cimento.

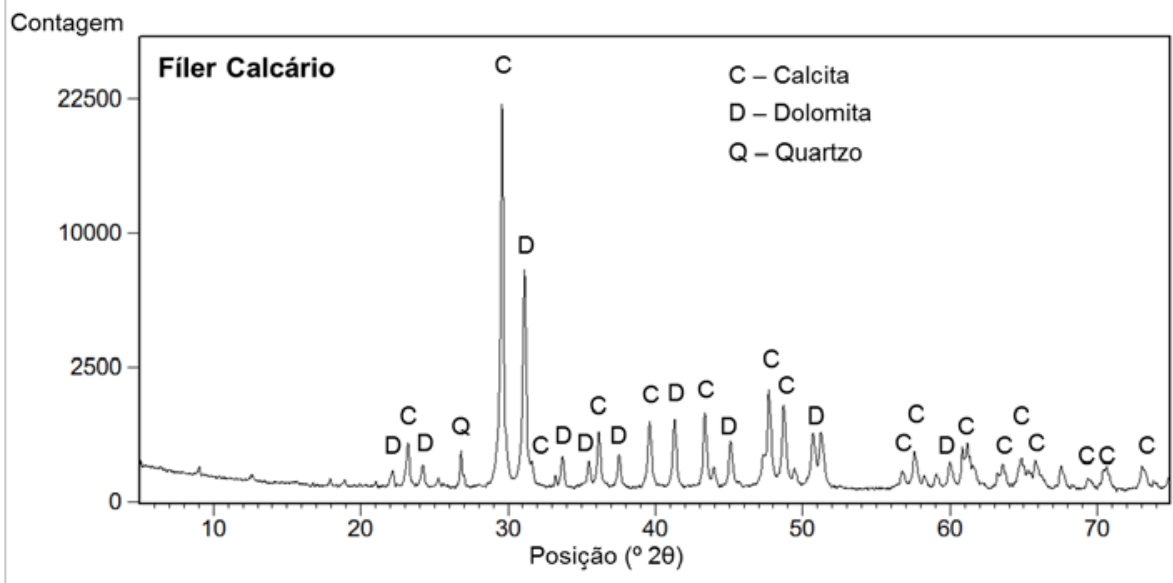

Figura 5: Difratograma de raios-X da amostra de fíler calcário. 


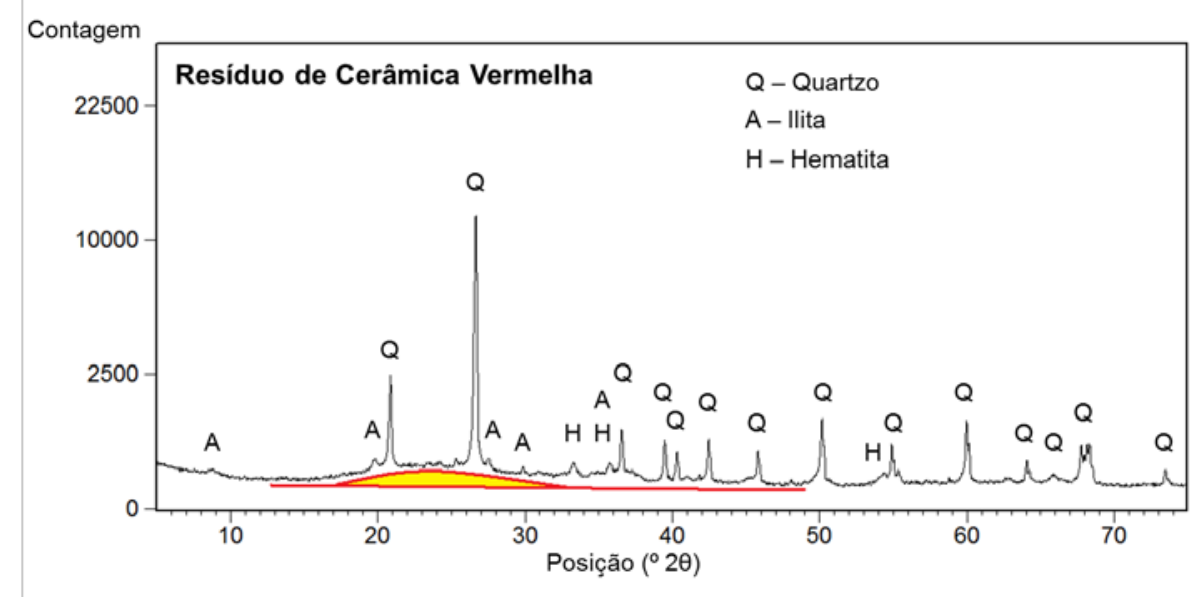

Figura 6: Difratograma de raios-X da amostra de material cerâmico.

\subsection{Reação álcali-sílica}

A Figura 7 apresenta a evolução da expansão das barras de argamassa devido à reação álcali-sílica ao longo de 66 dias. A argamassa de cimento CP V - ARI, considerado cimento-padrão, conforme as recomendações da NBR 15.577-4/2008 [19], foi utilizada para classificar, de acordo com os critérios da NBR 15.577-1/2008 [27], a potencialidade inócua ou reativa do agregado empregado neste experimento. Como a expansão aos 30 dias $(0,15 \%)$ foi inferior à expansão limite de $0,19 \%$ estabelecida na referida norma, o agregado foi classificado como potencialmente inócuo para uso em concreto. A classificação do agregado baseada na norma brasileira difere daquela obtida por Tiecher [16] e Valduga [17] por meio da norma ASTM C 1260/2007 [18], a qual atribuiu potencialidade reativa ao agregado. Assim sendo, há que se considerar a possibilidade deste agregado apresentar reação álcali-sílica em virtude da expansão, aos 14 dias, situar-se na região de incerteza estabelecida pela norma americana ${ }^{2}$, o que requer, preventivamente, a adoção de medidas mitigadoras.

A influência das adições minerais deste trabalho na mitigação da expansão das argamassas, conforme as recomendações da NBR 15.577-1/2008 [27], deve ser avaliada na idade de 16 dias, quando a expansão deve ser inferior a $0,10 \%$. Neste estudo, além da idade recomendada pela norma, optou-se pelo monitoramento do comportamento das argamassas em idades maiores, a fim de melhor avaliar a influência do RCV (Figura 7), onde também estão apresentados os resultados de expansão, aos 16 dias, das argamassas contendo os diferentes materiais ligantes. De fato, o cimento CP V - ARI, utilizado como padrão, resultou em um sistema com expansão superior ao limite recomendado pela norma, apesar da análise preliminar do agregado, conforme a NBR 15.577-1/2008 [27], não demandar medida mitigadora.

\footnotetext{
${ }^{2}$ A norma ASTM C 1260/2007 estabelece a expansão de 0,10\% aos 14 dias como limite para considerar o agregado inócuo, até $0,20 \%$ aos 28 dias para potencialmente reativo e acima de $0,20 \%$ aos 28 dias para agregado reativo.
} 


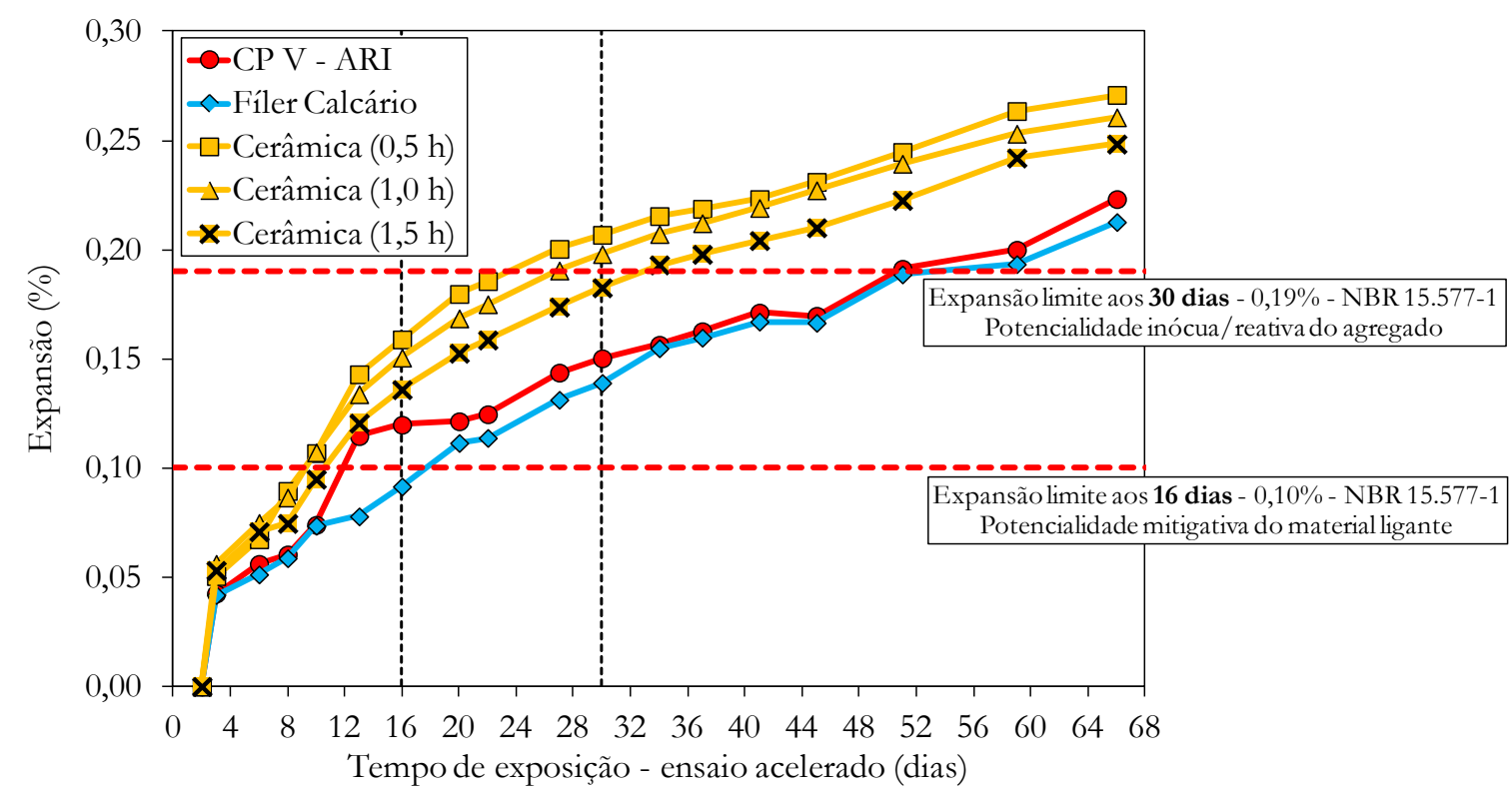

Figura 7: Reação álcali-sílica: evolução da expansão média das barras de argamassa com 100 \% de cimento comparado com substituição de $10 \%$ do cimento por adições minerais.

A utilização do fíler calcário na composição do material ligante aparentemente atribuiu potencial de mitigação a esta adição, embora, estatisticamente, o resultado possa ser considerado idêntico ao valor limite de $0,10 \%$. Os efeitos físicos do fíler calcário interferem na microestrutura da matriz hidratada, o que propiciou redução da expansão da argamassa.

O RCV, independentemente da finura, além de não mitigar a reação álcali-sílica, propiciou a expansão da argamassa a valores superiores ao observado na referência. O maior tempo de moagem do resíduo de cerâmica vermelha tendeu a reduzir a expansão da argamassa.

A análise geral, ao longo de 66 dias, mostra que o comportamento expansivo da argamassa com fíler calcário tende a se equiparar à série de referência após 20 dias, mantendo esta tendência ao longo do período estudado. Já a série contendo RCV, nas diferentes finuras, tende a manter maior expansão em comparação à série de referência para as idades avaliadas. De fato, a maior expansão ocorre sempre na amostra de resíduo de cerâmica vermelha com menor tempo de moagem.

Cabe salientar que a utilização de RCV, nos tempos de moagem de 0,5 e 1,0 hora, atribuiu potencialidade reativa às respectivas argamassas, pois estas superaram o valor limite de expansão de 0,19\% aos 30 dias. A argamassa contendo o resíduo moído por 1,5 horas apresentou expansão próxima ao limiar normativo para a referida idade, o que atribui a esta adição mineral incerteza sobre a sua adequabilidade para a mitigação da reação álcali-sílica. Resumindo, o resíduo de cerâmica vermelha potencializa a expansão da argamassa quando da presença de álcalis na solução aquosa dos poros da matriz hidratada.

\subsection{Resistência ao ataque por sulfato de sódio}

4.4.1 Avaliação de 14, 28 e 42 dias, de acordo com a NBR 13.583/2014:

A resistência ao ataque por sulfatos está relacionada ao teor de compostos hidratados expansivos formados na matriz endurecida da argamassa exposta à solução de sulfato de sódio em relação à mesma argamassa, curada em água saturada de cal, onde não há formação de compostos expansivos oriundos de fonte externa de íons sulfato. A expansão, decorrente da formação de etringita secundária e sulfato de cálcio di-hidratado (gipsita) na estrutura porosa da matriz hidratada, resulta em esforços internos que expandem a argamassa e podem levá-la à fissuração [28-29], como ilustra a Figura 8, em corpos de prova usados no monitoramento de expansão neste trabalho. De fato, a expansão pode ocorrer até certo limite, caso contrário, o compósito de cimento Portland pode perder sua integridade, o que o caracteriza como material não resistente ao ataque por sulfatos, conforme verificado por Ouyang et al. [30]. A Figura 9 apresenta a expansão resultante da argamassa de refe- 
rência e das argamassas com adições de fíler calcário ou material cerâmico na composição do material ligante, conforme estabelece a NBR 13.583/2014 [13].

Os resultados da Figura 9, com leituras de 14, 28 e 42 dias (como recomenda a NBR 13.583/2014 [13]), indicam um comportamento diferenciado do resíduo de cerâmica vermelha, evidenciando incerteza quanto a sua eficiência em mitigar o ataque por sulfato de sódio. Verifica-se que no caso do material de cerâmica vermelha moída por 1,0 hora, a expansão foi maior do que a série de referência. Para diferenciar as médias, foi aplicada a análise de variância em conjunto com o teste de Tukey, indicando que aos 42 dias as médias podem ser separadas em 3 grupos em ordem crescente de resultados: 1 - cerâmica 0,5 e 1,5 horas de moagem; 2 - CP V-ARI e Fíler calcário; 3 - cerâmica 1,0 horas de moagem.

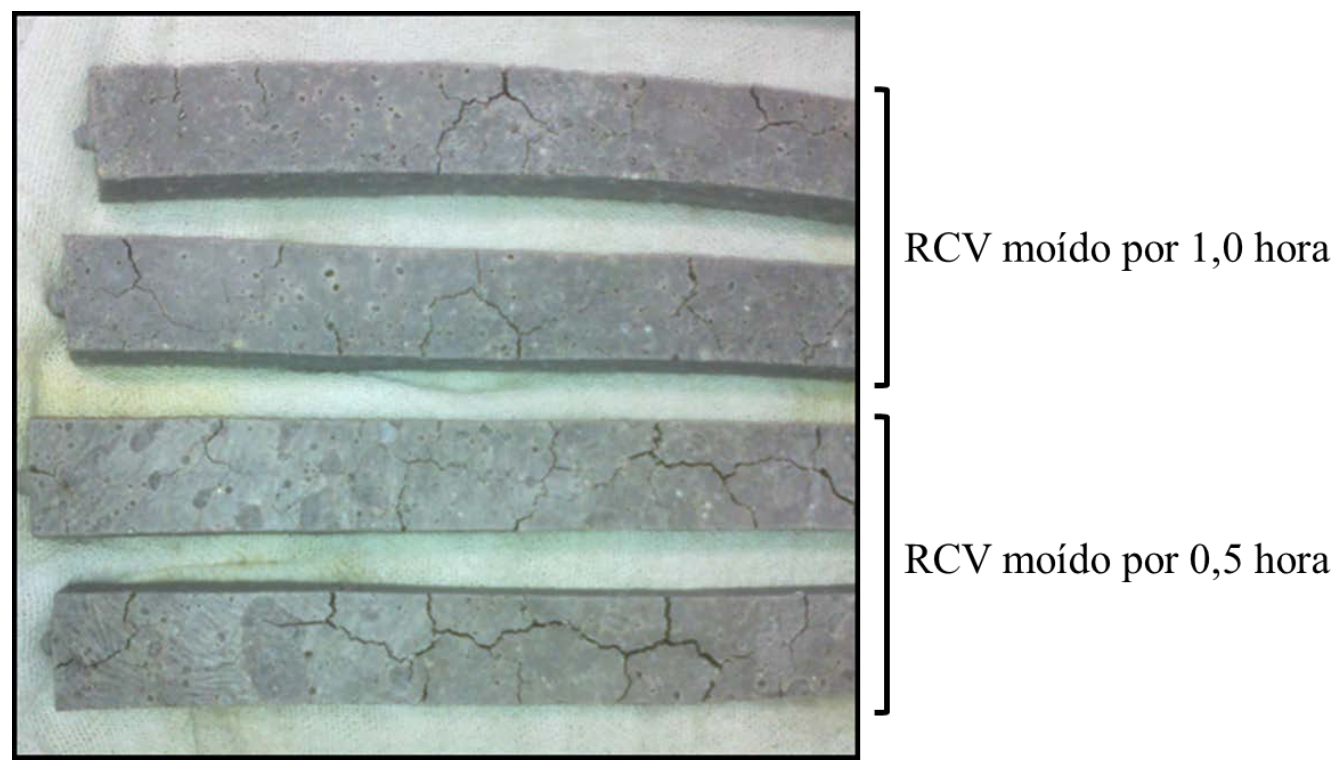

Figura 8: Exemplo do efeito de fissuração provocado pelo ataque do sulfato de sódio em compósito de cimento Portland, após 210 dias de exposição [ensaio conforme preconiza a NBR 13.583 (ABNT, 2014) [13]].

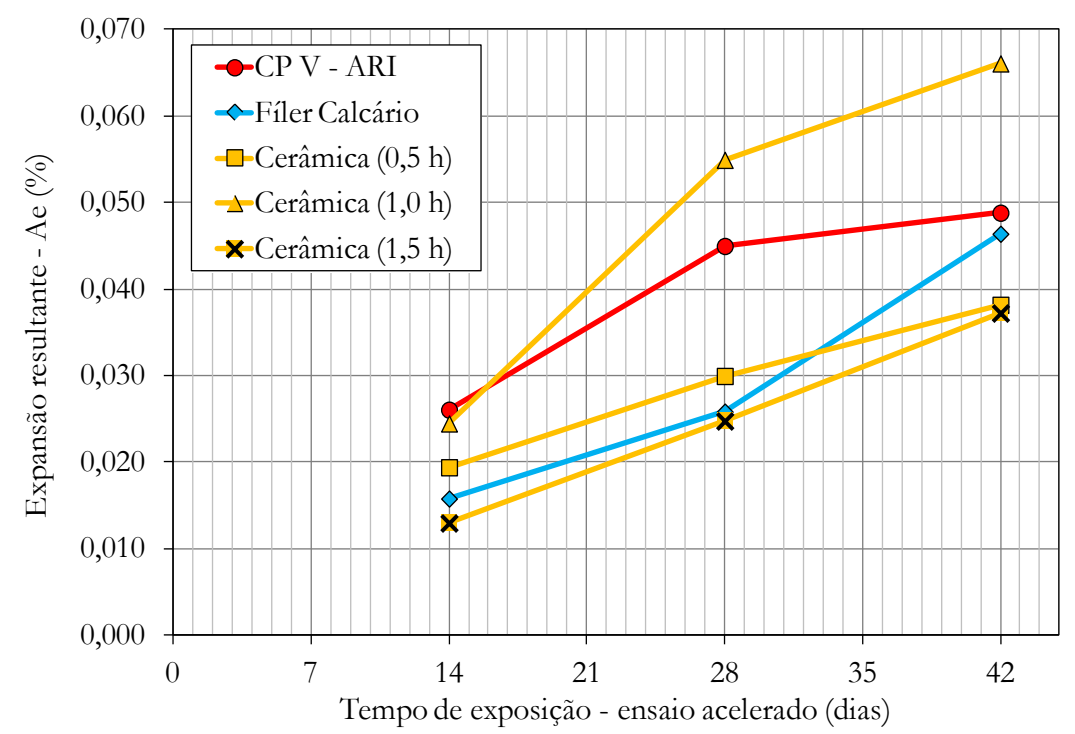

Figura 9: Expansão resultante das argamassas contendo adições minerais na composição do material ligante, conforme preconiza a NBR 13.583 [13] quanto ao ataque por sulfato de sódio.

No caso da exposição da argamassa de cimento Portland à solução de sulfato de sódio, ocorre a con- 
versão do monossulfoaluminato de cálcio hidratado (AFm) em etringita secundária (AFt) e o consumo de íons cálcio em solução para a precipitação de gipsita [31-34]. A formação da etringita secundária está relacionada ao teor de aluminato tricálcico $\left(\mathrm{C}_{3} \mathrm{~A}\right)$ presente na composição do cimento Portland que, ao hidratar-se na presença de gipsita, forma etringita (AFt) seguido de conversão para monossulfoaluminato de cálcio hidratado (AFm). A precipitação da gipsita decorrente do ataque por sulfatos requer fonte de íons cálcio, o que resulta em consumo destes íons contidos na solução aquosa dos poros. Estas reações foram detalhadas no modelo de ataque por sulfatos apresentado por Zuo et al. [35].

A portlandita é o principal responsável em repor a concentração de íons cálcio da solução e, na sua ausência, haverá descalcificação do silicato de cálcio hidratado (C-S-H) para prover íons cálcio à solução e precipitar a gipsita decorrente do ataque por sulfatos [30, 36-37]. Tais reações envolvem os produtos hidratados do cimento Portland, porém cabe salientar que a hidratação das fases anidras também ocorre, no ensaio acelerado preconizado pela NBR 13.583/2014 [13], em paralelo ao ataque por sulfatos e, portanto, os produtos deletérios formados podem incorporar parte dos constituintes das fases anidras disponibilizadas na solução aquosa dos poros.

O fíler calcário, a priori, reduz a expansão resultante, porém, aos 42 dias, há comportamento semelhante ao observado na argamassa de referência. A diminuição no teor de cimento Portland reduz, consequentemente, o teor de $\mathrm{C}_{3} \mathrm{~A}$ no sistema e, também, o teor de portlandita formado na hidratação. Desta forma, haverá menor teor de monossulfoaluminato de cálcio hidratado a ser convertido em etringita. Porém, no que se refere à microestrutura, o fíler calcário resulta em maior porosidade do sistema e menor resistência à compressão, haja vista o volume de água de mistura ser mantido constante, o que significa que a relação a/c é superior. A maior porosidade, associada à interconectividade entre os poros permite maior acesso da solução de sulfato de sódio ao interior das barras de argamassa, propiciando maior interação dos íons sulfatos com a matriz hidratada e, consequentemente, maior formação de produtos deletérios. A mescla destes dois efeitos contrários, aparentemente se equilibra aos 42 dias de ensaio fazendo com que o resultado final de expansão se aproxime do comportamento apresentado pela argamassa de referência.

4.4.2 Resistência ao ataque por sulfato de sódio - Avaliação a longo prazo, entre 42 dias e 210 dias

Após a análise baseada na norma NBR 13.583/2014 [13], a qual preconiza leituras de 14, 28 e 42 dias, esta pesquisa teve prosseguimento com a exposição à solução de sulfato de sódio processando novas medições a 70, 140 e 210 dias para verificar o comportamento dos corpos de prova submetidos a idades mais avançadas.

A Figura 10 apresenta os resultados do monitoramento da expansão até 210 dias. Na idade de 70 dias, o comportamento das argamassas se assemelha ao observado aos 42 dias, indicando que o fíler calcário e as cerâmicas moídas não alteram significativamente a eficiência do compósito de cimento Portland frente ao ataque por sulfatos. Por outro lado, aos 210 dias as médias apresentam diferenças claras que foram interpretadas usando a análise de variância em conjunto com o teste de Tukey para a diferenciação de médias. O resultado foi que os dados podem ser divididos em 3 grupos em ordem crescente de resultados: 1 - Fíler calcário; 2 - CP V-ARI e cerâmica 1,5 horas de moagem; 3 - cerâmica com 0,5 e 1,0 horas de moagem.

Desse modo, nas leituras de 140 e 210 dias ocorrem mudanças significativas nas argamassas contendo cerâmica vermelha moída por 0,5 e 1,0 horas, as quais apresentam expansão mais elevada do que a série de referência. Por outro lado, a cerâmica moída por 1,5 horas apresentou resultado indicativo de equivalência com a série de referência. Isto pode ser explicado a partir de duas propriedades distintas entre si, todavia, conjuntas no processo de expansão, a física e a química.

Na física, a elevada finura do material pode ter elevado o fator de empacotamento de partículas, dificultando, desta forma, a difusão de íons agressivos ao interior da pasta, o que explica a menor expansão resultante em curtos intervalos de tempo de exposição. Contudo, a partir do momento em que a difusão dos íons agressivos começa a ser facilitada, ou seja, há a manifestação de microfissuras, a resistência das barras passa a depender, em maior grau, das propriedades químicas. Desse modo, observa-se que a adição de material cerâmico possui uma tendência mais expansiva do que a série referência. Isto pode ser explicado pelo elevado teor de aluminatos presente na composição química deste material. Quando comparadas, a série de referência apresenta teor de 3,59\% de $\mathrm{Al}_{2} \mathrm{O}_{3}$ enquanto que, somente o material cerâmico, apresenta teor de $30,31 \%$ deste composto, influenciando diretamente na formação de etringita $\left(3 \mathrm{CaO} \cdot \mathrm{Al}_{2} \mathrm{O}_{3} \cdot 3 \mathrm{CaSO}_{4}\right.$. $32 \mathrm{H}_{2} \mathrm{O}$ ), principal responsável pela expansão de barras de argamassa expostas ao sulfato de sódio [2, 34, 38].

O caso da série composta por material cerâmico com moagem de 1,5 horas pode ser analisado sob o 
ponto de vista da melhoria no nível do empacotamento dos grãos. Neste caso, este efeito de empacotamento de partículas pode ter compensado o efeito químico fazendo com que a série com material cerâmico com moagem de 1,5 horas apresentasse resultado similar à série de referência para 210 dias de exposição.

Deve-se notar também que, nas idades mais avançadas, o fíler calcário passa a se destacar positivamente, como também constatado no trabalho de Ghrici et al. [39]. Portanto, este material indica ser eficiente, no que diz respeito à redução do efeito do ataque por sulfato de sódio em compósitos de cimento Portland. Sendo este material inerte, pode-se considerar que o efeito de melhoria no nível do empacotamento de partículas e redução da quantidade de aluminato tri-cálcico no sistema são os responsáveis por esta melhora.

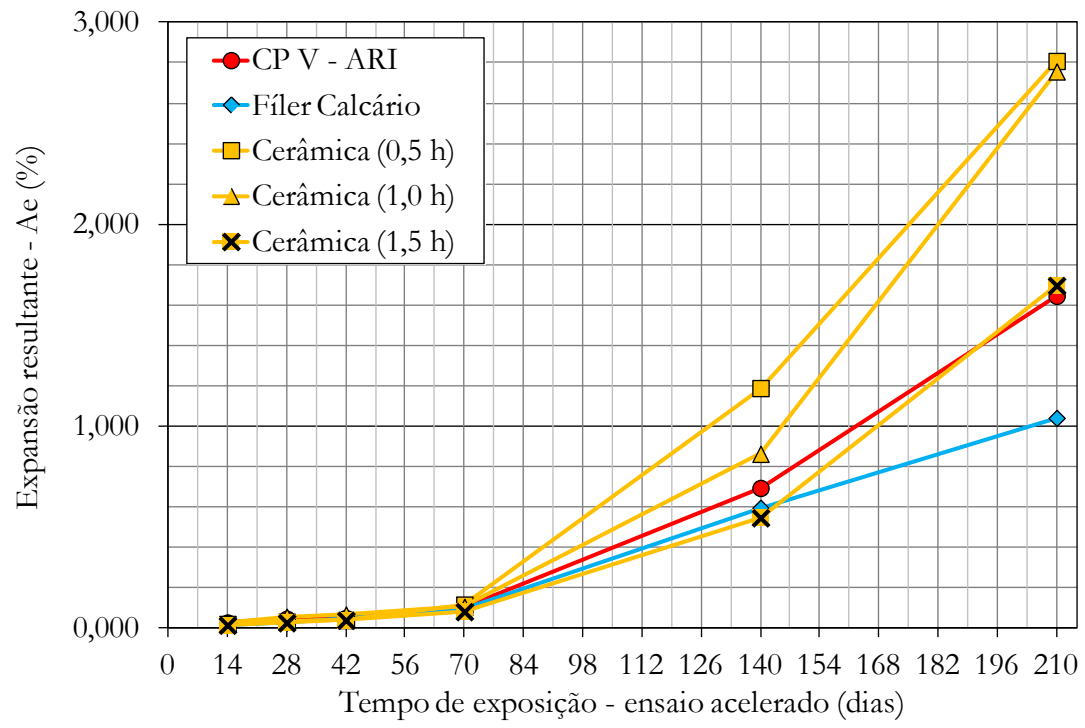

Figura 10: Expansão resultante por ataque por sulfato de sódio até 210 dias de exposição, conforme metodologia de ensaio da NBR 13.583/2014 [13].

\section{CONCLUSÕES}

Este trabalho teve como foco o efeito da incorporação de RCV para a execução de concretos e argamassas de cimento Portland submetidos a condições favoráveis para a ocorrência da RAS e ao ataque por sulfato de sódio. Os resultados obtidos nos ensaios permitem as seguintes conclusões:

O RCV cominuído foi classificado como adição mineral pozolânica quando avaliado por meio do ensaio Chapelle modificado, apesar dos resultados dos ensaios indiretos de avaliação da atividade pozolânica (IAP com cal e IAP com cimento) não atribuírem pozolanicidade ao material cerâmico, independentemente da finura. O maior tempo de moagem do RCV incrementou o consumo de cal por atividade pozolânica e a resistência à compressão das argamassas de cal ou cimento.

A potencialidade pozolânica do RCV requer adequada cominuição do material para que este cumpra, também, os requisitos classificatórios relacionados à resistência à compressão. Esta tendência ficou evidente nos resultados de IAP com cal e IAP com cimento Portland. O maior tempo de moagem aumenta o empacotamento das partículas e, consequentemente, a resistência à compressão da argamassa. Com base nos dados de granulometria a laser, conclui-se que quanto maior o tempo de moagem do RCV, mais fino o material, indicando que não foi atingido o tempo de redução de eficiência de moagem relatado por Luz et al. [40] e Bristot [41], que é o limite de tempo de moagem em que mesmo aumentando o tempo de operação do moinho, a curva granulométrica do pó produzido não indica aumento do teor de grãos mais finos.

A DRX indica haver um tênue halo amorfo no RCV, o que disponibiliza sílica e alumina para a interação com a cal e, também, alumina para a formação de etringita secundária quando da exposição à solução de sulfato de sódio. Portanto, o RCV atua como material pozolânico e fonte de sílica e alumina amorfas susceptíveis aos íons sódio (RAS) e íons sulfato.

O fíler calcário não reduziu de forma significativa os efeitos da RAS e do ataque por sulfato, apesar de promover redução da portlandita e alteração no nível de empacotamento de partículas. De modo geral, pode-se considerar que a série com fíler calcário e a série de referência são equivalentes, exceto quando da 
análise do ataque por sulfato em idades avançadas (210 dias), onde a argamassa contendo fíler calcário apresentou melhor desempenho.

No caso do RCV, os valores de expansão por RAS, em todos os casos, foram superiores aos apresentados pela série de referência, indicando que este material não é recomendado para uso em concretos empregados em conjunto com agregado reativo. No ataque por sulfato, o RCV aumentou a expansão da argamassa, apesar de que, na maior finura, o comportamento observado apresentou desempenho similar ao da argamassa de referência.

A complexidade da avaliação do efeito de adições minerais nos resultados de RAS e de ataque por sulfato está na coexistência de efeitos divergentes simultâneos, apresentados detalhadamente pelos autores na Tabela 6, a qual indica que podem existir efeito químico, efeito de mudança no nível do empacotamento de partículas, efeito de substituição parcial do cimento e alteração da relação água/cimento.

Tabela 6: Efeitos da substituição parcial de cimento Portland por adições em casos de ataque por sulfato de sódio e por álcali-sílica.

\begin{tabular}{|c|c|c|}
\hline Classificação do efeito & Descrição do efeito & Consequência \\
\hline químico & $\begin{array}{c}\text { depende da interação química, se o } \\
\text { material é pozolânico ou se a origem } \\
\text { das reações são outras }\end{array}$ & pode aumentar ou diminuir a expansão \\
\hline $\begin{array}{l}\text { mudança no nível do empaco- } \\
\text { tamento de partículas }\end{array}$ & $\begin{array}{l}\text { aumento no nível do empacotamento } \\
\text { pode ser causado pela inclusão de } \\
\text { materiais muito finos em substituição } \\
\text { parcial do cimento Portland }\end{array}$ & $\begin{array}{l}\text { aumento no nível do empacotamento } \\
\text { reduz a expansão por dificultar o ingresso } \\
\text { de solução de sulfato e de água (impor- } \\
\text { tante no caso de RAS) no compósito }\end{array}$ \\
\hline substituição parcial do cimento & $\begin{array}{l}\text { diminui a quantidade de } \mathrm{C}_{3} \mathrm{~A} \text { e de } \\
\text { portlandita no sistema }\end{array}$ & $\begin{array}{l}\text { influencia a cinética do ataque por sulfa- } \\
\text { tos (pela redução do } \mathrm{C}_{3} \mathrm{~A} \text { e da portlandi- } \\
\text { ta) }\end{array}$ \\
\hline $\begin{array}{l}\text { redução da relação } \\
\text { água/cimento }\end{array}$ & $\begin{array}{c}\text { se a adição for inerte, a relação } \\
\text { água/ligante efetiva é aumentada, } \\
\text { apresentando tendência de aumento } \\
\text { da porosidade }\end{array}$ & $\begin{array}{l}\text { maior relação água/ligante resulta em } \\
\text { porosidade maior, facilitando acesso de } \\
\text { água (importante no caso de RAS) e so- } \\
\text { lução de sulfatos }\end{array}$ \\
\hline
\end{tabular}

O presente trabalho evidenciou que o uso do RCV como adição mineral pozolânica requer cautela, haja vista que as propriedades de durabilidade avaliadas apresentaram menor desempenho quando da incorporação deste resíduo em substituição parcial ao cimento Portland à matriz cimentícia das argamassas.

Por fim, o tempo de avaliação dos ensaios acelerados propostos nas normas de RAS e ataque por sulfato pode ser muito curto, pois nas idades mais avançadas, os resultados indicaram tendências diferentes e mais conclusivas quando comparados aos resultados obtidos nas idades estabelecidas nas respectivas normas.

\section{AGRADECIMENTOS}

Os autores agradecem o apoio do Programa de Pós-graduação em Engenharia de Construção Civil da Universidade Federal do Paraná (DCC-PPGECC-UFPR), da Universidade Estadual de Ponta Grossa (UEPG), da Universidade Federal do Oeste da Bahia (UFOB), do Instituto de Pesquisas Tecnológicas do Estado de São Paulo (IPT) e do Conselho Nacional de Desenvolvimento Científico e Tecnológico (CNPq).

\section{BIBLIOGRAFIA}

[1] GARCIA, E., CABRAL JUNIOR, M., QUARCIONI, V. A., et al. "Resíduo de cerâmica vermelha (RCV): uma alternativa como material pozolânico”, Revista Cerâmica Industrial, v. 19, n. 4, pp. 31 - 38, Julho/Agosto 2014.

[2] KOMLJENOVIC, M., BASCAREVIC, Z., MARJANOVIC, N., et al. "External sulfate attack on alkaliactivated slag”, Construction and Building Materials, v. 49, pp. 31-39, 2013.

[3] VIEIRA, A. A. P. Estudo do aproveitamento de resíduos de Cerâmica vermelha como substituição Pozolânica em argamassas e concretos, Dissertação de M.Sc., Universidade Federal da Paraíba, Paraíba, 2005.

[4] MATIAS, G., FARIA, P., TORRES, I., et al., "Argamassas de cal aérea com resíduos de cerâmica” In: Congresso de Argamassas de Construção da APFAC, 4 ${ }^{\circ}$ Coimbra, 2012. 
[5] FARIAS FILHO, J., ROLIM, J. S., TOLEDO FILHO, R. D. "Potencialidades da metacauolinita e do tijolo queimado moído como substitutos parciais do cimento Portland”, Revista Brasileira de Engenharia Agrícola e Ambiental, v. 4, n. 3, pp. 437-444, 2000.

[6] QUARCIONI, V. A., CHOTOLI, F. F., COELHO, A. C. V., et al. "Indirect and direct Chapelle's methods for the determination of lime consumption in pozzolanic materials", Ibracon Materials and Structures Journal, v. 8, n. 1, pp. 1- 7, February 2015.

[7] SENTHAMARAI, R. M., MANOHARAN, P. D. "Concrete with ceramic waste aggregate”, Cement and Concrete Composites, v. 27, pp. 910-913, 2005.

[8] SENTHAMARAI, R. M., MANOHARAN, P. D., GOBINATH, D. "Concrete made from ceramic industry waste: Durability properties”, Construction and Building Materials, v. 25, pp. 2413-2419, 2011.

[9] CABRAL, A. E. B., SCHALCH, V., DAL MOLIN, D. C. C., et al. "Desempenho de concretos com agregados reciclados de cerâmica vermelha”, Cerâmica, v. 55, pp.448-460, 2009.

[10] BRITO, J., PEREIRA, A. S., CORREIA, J. R. "Mechanical behaviour of non-structural concrete made with recycled ceramic aggregates”, Cement and Concrete Composites, v. 27, pp. 429-433, 2005.

[11] OLIVEIRA, L. A. P., GOMES, J. P. C., SANTOS, P. M. S. "The potential pozzolanic activity of glass and red-clay ceramic waste as cement mortars componentes", Construction and Building Materials, v. 31, pp. 197-203, 2012.

[12] ASSOCIAÇÃO BRASILEIRA DE NORMAS TÉCNICAS. NBR 15.577-5: Reação álcali-agregado. Parte 5: Determinação da mitigação da expansão em barras de argamassa pelo método acelerado, Rio de Janeiro, 2008.

[13] ASSOCIAÇÃO BRASILEIRA DE NORMAS TÉCNICAS. NBR 13.583: Cimento Portland - Determinação da variação dimensional de barras de argamassa de cimento Portland expostas à solução de sulfato de sódio, Rio de Janeiro, 2014.

[14] ASSOCIAÇÃO BRASILEIRA DE NORMAS TÉCNICAS. NBR 11.578: Cimento Portland composto, Rio de Janeiro, 1991.

[15] ASSOCIAÇÃO BRASILEIRA DE NORMAS TÉCNICAS. NBR NM 23: Cimento portland e outros materiais em pó - Determinação da massa específica, Rio de Janeiro, 2001.

[16] TIECHER, F. "Reação álcali-agregado: avaliação do comportamento de rochas do sul do Brasil quando se altera o cimento utilizado", Dissertação de M.Sc., Faculdade de Engenharia Civil, Universidade Federal do Rio Grande do Sul, Porto Alegre, RS, 2005.

[17] VALDUGA, L. "Influência das condições de ensaio da ASTM C 1260 na verificação da reação álcaliagregado", Tese de D.Sc., Escola de Engenharia, da Universidade Federal do Rio Grande do Sul, Porto Alegre, RS, Brasil, 2007.

[18] ASTM C - 1260/07: Standard test method for potential alkali reactivity of aggregates (mortar-bar method). Philadelphia, 2007. Section 4 (Construction), v. 04.02 (Concrete and aggregates), pp. 647-650.

[19] ASSOCIAÇÃO BRASILEIRA DE NORMAS TÉCNICAS. NBR 15.577-4: Reação álcali-agregado. Parte 4: Determinação da expansão em barras de argamassa pelo método acelerado, Rio de Janeiro, 2008.

[20] ASSOCIAÇÃO BRASILEIRA DE NORMAS TÉCNICAS. NBR 5.751: Materiais pozolânicos — Determinação da atividade pozolânica — Índice de atividade pozolânica com cal — Método de ensaio, Rio de Janeiro, 2012.

[21] ASSOCIAÇÃO BRASILEIRA DE NORMAS TÉCNICAS. NBR 5.752: Materiais pozolânicos — Determinação do índice de desempenho com cimento Portland aos 28 dias, Rio de Janeiro, 2012.

[22] ASSOCIAÇÃO BRASILEIRA DE NORMAS TÉCNICAS. NBR 7214: Areia normal para ensaio de cimento - Especificação, Rio de Janeiro, 2012.

[23] ASSOCIAÇÃO BRASILEIRA DE NORMAS TÉCNICAS. NBR 15.895: Materiais pozolânicos - Determinação do teor de hidróxido de cálcio fixado - Método Chapelle modificado, Rio de Janeiro, 2010.

[24] RAVERDY, M.; BRIVOT, F.; PAILLÈRE, A. M.; BRON, R. Appréciation de l’ ativité pouzzolanique des constituants secundaries. In: Congrés Internacional de la Chimie des Ciments, Paris, $7^{\text {a }}$ e., v.II e IV, 1980.

[25] ASSOCIATION FRANÇAISE DE NORMALISATION. NF P 18-513: Métakaolin, addition pouzzolanique pour bétons - Définitions, specifications, critères de conformité, 2012.

[26] ASSOCIAÇÃO BRASILEIRA DE NORMAS TÉCNICAS. NBR 12.653: Materiais pozolânicos — Requisitos, Rio de Janeiro, 2012. 
[27] ASSOCIAÇÃO BRASILEIRA DE NORMAS TÉCNICAS. NBR 15.577-1: Agregados - Reatividade álcali-agregado. Parte 1: Guia para avaliação da reatividade potencial e medidas preventivas para uso de agregadosem concreto, Rio de Janeiro, 2008.

[28] SANTHANAM, M., COHEN, M. D., OLEK, J. "Mechanism of sulfate attack: A fresh look Part 1: Summary of experimental results”, Cement and Concrete Research, v. 32, pp. 915-921, 2002.

[29] SANTHANAM, M., COHEN, M. D., OLEK, J. "Mechanism of sulfate attack: A fresh look Part 2: Proposed mechanisms”, Cement and Concrete Research, v. 33, pp. 341-346, 2003.

[30] OUYANG, W., CHEN, J. K.., JIANG, M. Q. "Evolution of surface hardness of concrete under sulfate attack”, Construction and Building Materials, v. 53, pp. 419-424, 2014.

[31] MEHTA, P. K., MONTEIRO, P. J. M. Concreto: estruturas, propriedades e materiais, São Paulo, Pini, 2008.

[32] BONAKDAR, A., MOBASHER, B. "Multi-parameter study of external sulfate attack in blended cement materials”, Construction and Building Materials, v. 24, pp. 61-70, 2010.

[33] AYE, T., OGUCHI, C. T. "Resistence of plain and blended cement mortars exposed to severe sulfate attacks”, Construction and Building Materials, v. 25, pp. 2988-2996, 2011.

[34] OLIVEIRA, I., CAVALARO, S. H. P., AGUADO, A. "New kinetic model to quantify the internal sulfate attack in concrete”, Cement and Concrete Research, v. 43, pp. 95-104, 2013.

[35] ZUO, X. B., SUN, W., YU, C. "Numerical investigation on expansive volume strain in concrete subjected to sulfate attack”, Construction and Building Materials, v. 36, pp. 404-410, 2012.

[36] MONTEIRO, P. J. M.; KURTIS, K. E. “Time to failure for concrete exposed to severe sulfate attack”, Cement and Concrete Research, v. 33, pp. 987-993, 2003.

[37] NEVILLE, A. "The confused world of sulfate attack on concrete”, Cement and Concrete Research, v. 34, pp.1275-1296, 2004.

[38] CHEN, J. K., JIANG, M. Q. “Long-term evolution of delayed ettringite and gypsum in Portland cement mortars under sulfate erosion”, Construction and Building Materials, v. 23, pp. 812-816, 2009.

[39] GHRICI, M., KENAI, S., MANSOUR, M. S. "Mechanical properties and durability of mortar and concrete containing natural pozzolan and limestone blended cements",Cement and Concrete Composites, v. 29, pp. 542-549, 2007.

[40] LUZ, A. B., ALMEIDA, S. L. M., SAMPAIO, J. A. Tratamento de Minérios, Rio de Janeiro, CETEM, 2004.

[41] BRISTOT, V. M. "Ferramental para prensagem hidráulica de esferoides de alumina”, Dissertação de M.Sc., Escola de Engenharia da Universidade Federal do Rio Grande do Sul, Porto Alegre, RS, 2008. 